\title{
EL HORROR SE QUEDA EN CASA
}

\author{
FRANCISCO DE LEÓN \\ Universidad Autónoma Nacional de México \\ Instituto Tecnológico de Estudios Superiores de Monterrey
}

\begin{abstract}
Desde que tengo memoria, siempre me sentí atraído por los temas ocultos y fantasmales. De niño me encantaba sentarme con mis hermanos a escuchar relatos de mi madre, una hija de españoles a quien le tocó nacer y crecer en las selvas tropicales de Limón, hasta que a los quince años su familia se trasladó a San José, en el centro del país y con un clima más benigno, donde empezó a llevar una vida más refinada. Como descendiente de Galicia, tenía en su haber una buena cuota de historias de brujas y hechiceros, algunos de estos incluso quemados por la Inquisición. A este caudal de cuentos macabros provenientes de la vieja Europa vinieron a sumarse historias de vudú, obeah y pocomía originarias de los negros de Limón y de Jamaica, entre cuyos ritos y costumbres le tocó crecer, a pesar de los esfuerzos de sus padres para que no se mezclara con los habitantes del pueblo, un caserío situado a la orilla del mar Caribe, no muy lejos de Londonia, donde mi abuelo había ido a parar ya no me acuerdo cómo ni por qué. Mi madre, que siempre fue extrovertida y curiosa, gustaba de meterse en casa de sus amiguitas y vecinas, donde seguramente en más de una ocasión le tocó oír y ver cosas fantásticas como las que luego nos contara.
\end{abstract}

José Ricardo Chaves

Pré́mbulo

Las líneas anteriores abren "Rollo de vuelo", texto que forma parte de los Cuentos tropigóticos; en ellas se delata el espíritu del que el autor busca dotar a cada una de las narraciones incluidas en este libro. Y es que este curioso concepto (cuya creación Chaves atribuye a la escritora Rosa Beltrán) no se refiere a una mera adaptación de los temas empleados por los góticos en latitudes distintas a las de su origen, sino que se refiere a un proceso complejo en el cual las formas 
estéticas, narrativas y sensibles sufren una transformación a partir de la fusión de estilos y tópicos. Afirma el autor,

La entelequia tropigótica, al tiempo que asume la analogía como forma de movimiento por espejos, no olvida a su compañera intelectual, la ironía, que introduce en espiral las dimensiones del humor, del distanciamiento, del escepticismo. Ya los románticos advirtieron que crítica sin ironía se convierte en dogma bajo el signo de Medusa. En los cuentos tropigóticos las mansiones victorianas -cuando las hay- pueden levantarse tanto en la selva tropical centroamericana como en la colonia Roma de la ciudad de México o en algún lugar incierto entre aquí, allá y acullá. El elemento fantástico y la realidad a veces aparecen, también lo numinoso, la sociología de la guerra, el retuerce Psicológico, las vísceras de la carnicería, el fetichismo de la cabellera y la multiplicación del yo. (Chaves 1997: 6-7)

Si bien José Ricardo Chaves usa la noción de lo tropigótico para hablar de sus originales cuentos, atrevo ahora un movimiento que lo lleve a otras formas de expresión, como el cine. Y es que, al acercarse a las atmósferas logradas por muchos directores latinoamericanos de cine de géneros de horror y fantástico, es posible notar una mezcla de sensibilidades, de ambientes que, si bien particularizan la situación presentada en escena, universalizan las emociones. Así, ciudades, haciendas, islas ven rota su cotidianeidad ante la irrupción de lo extraño. Los gélidos y oscuros escenarios del gótico dan paso a ardientes climas, a grandes ciudades cuyas arquitecturas de nada sirven cuando los personajes en turno enfrentan a lo desconocido.

Tal es el caso de las dos cintas de las que me ocuparé en este texto: $L a$ invención de Cronos (1993), del director mexicano Guillermo del Toro, y Juan de los muertos (2012), del argentino Alejandro Brugués. En ambos casos abunda un espíritu de originalidad dentro de temas muy bien conocidos: el vampiro y el zombi, respectivamente. Por un lado, Del Toro no solo llevará al vampiro a la ciudad de México, cambiando los castillos y los ambientes victorianos por fábricas, barrios viejos y tiendas de antigüedades, sino que en una curiosa vuelta de tuerca, navegará por alquimias de la Nueva España para la génesis de su inmortal bebesangre. Por su parte, Brugués ubica al zombi en Cuba para transformarlo en una divertida y atrevida crítica social y cultural. No solo eso, sino que en ambos casos se abordarán temas (desde visiones personales, claro está) que causan un profundo efecto en el imaginario latinoamericano. Lo familiar, por ejemplo, ocupa un lugar central en sus narraciones, pues, pese a que lo familiar ha visto alteradas sus estructuras tradicionales, continúa siendo una institución fundamental en la cultura latinoamericana. Así pues, romper su armonía (tan disonante como pueda resultar) representa un duro golpe. Ahora bien, cuando dicha ruptura ocurre por la invasión de un elemento desconocido y extraño, el golpe será aún mayor. De este modo, al enfrentarse a lo desconocido, los personajes de ambos filmes harán todo lo que puedan para defender a aquellos que les son más queridos. 
Freud, en su texto "Lo ominoso", afirma que esta fuerza ve su origen en el espacio doméstico, pues en este, en sus sombras y espacios ocultos, se muestran cosas cuyas formas parecen cobrar vida. Toda forma ajena a lo que cotidianamente se puede reconocer es una ruptura que engendra distintas imaginerías. Lo siniestro es, así, algo ajeno al orden familiar de las cosas y, sin embargo, se encuentra integrado en ello.

Ya en el propio género de horror, al cual es posible circunscribir Cronos y Juan de los muertos (aunque esta última se fusione con la comedia), la invasión de lo extraño, de un elemento inexplicable es, insisto, fundamental, pero fundamental es también que este elemento invasor lleve en sí una carga de familiaridad, un algo identificable que se altera de manera apenas perceptible y, por ello, terrible. Lo monstruoso viene desde fuera, pero se asienta profundamente en el interior de quien lo recibe, pues es el interior humano el que le da su razón de ser, su verdadero impulso.

\section{LA INMORTALIDAD ES UN INSECTO QUE NOS CONSUME LA SANGRE}

La invención de Cronos, ópera prima del director oriundo de Guadalajara, Jalisco, presenta el nacimiento de un estilo hasta hoy identificable: seres monstruosos, niños poseedores de una inocente sabiduría acerca de los mundos fantásticos, ambientes cerrados, subterráneos y laberínticos, inmersos todos en un mundo reconocible. En un elemento que va a convertirse en una constante en su obra, la cinta abre con una narración en off que relata brevemente la historia del alquimista Uberto Fulcanelli (Mario Iván Martínez), quien, en 1536, con el afán de escapar a la Inquisición, desembarca en el puerto de Veracruz, en México. Posteriormente se ve convertido en relojero del virrey y sus trabajos lo llevan a inventar un aparato que le otorga la vida eterna. Un breve y largo salto temporal lleva la escena al desplome de una iglesia en 1937. De entre las víctimas del hecho surge la imagen de un hombre...

Es el alquimista. Su piel (blanca, casi transparente, como la de un lagarto que no ha salido al sol en décadas) tiene una apariencia más joven y suave. Tiene los ojos negros y profundos de un animal. Su corazón está atravesado por una pesada barra de hierro. Trata desesperadamente de arrancarla. Sus manos se empapan en sangre oscura, casi negra. Es inútil. En agonía murmura algo. Nos acercamos más, sus palabras se vuelven más claras.

ALQUIMISTA: SUo... tempore...

El alquimista ríe quedamente, incrédulo. Este sonido se suspende en el eco del lugar dando lugar a la escena un toque de locura, una pincelada atroz.

VOZ EN OFF: Y entonces murió.

La mano del alquimista queda inmóvil sobre un trozo de cantera, imprimiendo con sangre el patrón de su palma. (Del Toro 1995: 14-15)

Me detengo en esta breve descripción para destacar un primer punto que considero fundamental: la génesis del monstruo. Llama la atención que, en lugar de tomar como mayor referente los orígenes del vampiro dados no solo por el folclor europeo, sino por la literatura y el cine, Del Toro recurre a la alquimia, lo 
cual lo convierte, creo, en el primer vampiro moderno de la cinematografía. Y es que a la manera en que hace Mary Shelley en su emblemática novela Frankenstein o el moderno Prometeo, el vampiro en Cronos es un ser venido de las manos del hombre, es, de hecho, un producto de su inventiva. Lo que para el joven estudiante de filosofía natural requiriere la paciente acumulación de partes de cadáveres y de un cuidadoso "ensamblaje", se ve traducido en Fulcanelli en la también paciente labor del relojero. Su invención otorga ya no únicamente una medida del tiempo sino una mecánica. Su funcionamiento es incomprensible para el espectador, pues al centro de un complejo sistema de engranajes y articulaciones arácnidas, se encuentra un insecto que dota de la energía necesaria al aparato para que este otorgue la inmortalidad a su usuario. Podría pensarse que justo este funcionamiento emparenta al vampiro más con la magia antigua que con los afanes modernos de Frankenstein, pero en ambas historias las constantes son, por un lado, la mecánica de la creación (aunque esta sea explicada simplemente con la idea de "la chispa de la vida" y con la imagen de la invención del alquimista, respectivamente) y la morfología monstruosa, su biología, por el otro. Es la suma de estos factores lo que da razón de ser a lo monstruoso. En ninguno de los casos existe la intervención de un elemento sobrenatural, no se trata de una posesión demoníaca, ni nada por el estilo: por el contrario, todos los elementos que se identifican se encuentran en la naturaleza, aunque dicha forma de naturaleza no quede del todo explicada, sino bajo el velo de la extraña ciencia de los creadores.

La alquimia no es una ciencia propiamente dicha, pero sus búsquedas ya no se hallan en la magia, sino en la naturaleza. La creación del Homúnculo, el anhelado encuentro con la piedra filosofal pueden resultar ajenas al lector contemporáneo, ingenuas incluso, pero no así su fuerza, su deseo proyectado de revelar los secretos de la mecánica del mundo ${ }^{1}$. De manera similar, en la cinta, la invención de Fulcanelli desvela, aunque no a simple vista, la mecánica del tiempo, la lógica del mundo, y la vence. El alquimista vive varios siglos, pero poco sabemos de esa vida prolongada gracias al misterioso aparato. Al final no queda sino un cuerpo destrozado por la mortal fragilidad de la obra humana, obra que sirve además para resguardar la imagen de un poder divino al que Fulcanelli ha confrontado y vencido, imagen que, al final del prólogo de la cinta, ha de servir de resguardo para la invención de Cronos.

Entra en escena Jesús Gris (Federico Luppi), un anciano comerciante de antigüedades que reparte su tiempo entre su tienda y la convivencia cotidiana con su mujer, Mercedes (Margarita Isabel), y su pequeña nieta, Aurora (único ser con el que Jesús parece abandonar las galas que le confiere su apellido). Entre las cosas que hay en su tienda, Jesús descubre la figura del arcángel que resguarda en un fondo falso la invención de Cronos. Con Aurora (Tamara Shanath) como un silencioso asistente, Jesús trata de descifrar el funcionamiento del aparato. Ante sus primeros movimientos, los exploradores lucen decepcionados; el hombre levanta sobre su mano la invención cuando, de repente, de esta salen seis

\footnotetext{
${ }^{1}$ Me ocupo ampliamente de estos temas en mi estudio Prometeo en llamas (2011).
} 
lancetas. Penetran entonces la mano de Jesús, quien se retuerce de dolor ante el terror de Aurora. Lo extraño ha roto en ese momento la cotidianeidad, lo monstruoso se hace presente en la gradual metamorfosis que sufrirá el protagonista.

A la par que se descubren los efectos de la invención de Cronos en Jesús Gris, se descubre también que hay alguien más que desea la inmortalidad artificial que el aparato brinda. El viejo y enfermo empresario De la Guardia (Claudio Brook) tiene en su poder el cuaderno en que el alquimista detalló la construcción del invento; sistemáticamente busca por todas partes figuras de arcángeles en aras de hallar aquel que contiene tan preciado objeto. En sus pesquisas le asiste su sobrino, Ángel (Ron Perlman). La ambición y el miedo a la muerte de De la Guardia pondrán a Jesús en un conflicto que no hace sino agravar su ya de por sí compleja situación.

A partir de dichos conflictos, se delata el segundo punto esencial que de la cinta pretendo abarcar: el mundo adulto en oposición al mundo infantil. En Cronos, así como en prácticamente toda la filmografía de Guillermo del Toro, los adultos son seres fragmentados, rotos por sus miedos o sus confrontaciones infructuosas con la vida. El propio director afirma: "En El espinazo del diablo, por ejemplo, todos los personajes adultos están incompletos. Uno es guapo pero brutal, el otro romántico pero impotente" (Serrano 2007).

Siguiendo un esquema similar, es posible tratar de acercarse a las grietas anímicas que caracterizan a los personajes adultos en Cronos:

a) En De la Guardia, se ha dicho ya, hay un profundo miedo a la enfermedad y a la muerte que viene a continuación; al decremento de fuerzas que la vejez representa.

b) En Ángel hay una brecha física: el deseo de operar su nariz para lucir "mejor" está presente de manera obsesiva a lo largo de toda la cinta. Se suma a lo anterior el hecho de que Ángel vive a la sombra de su tío. Solo desea que el anciano muera para heredar su imperio.

c) Mueve a Mercedes una profunda nostalgia: dar sus clases de tango, asistir al baile de año nuevo son los únicos reflejos de su aliento vital.

d) Finalmente, Jesús, vencido por su edad y sus fuerzas que decaen, atrapado en su cotidianeidad.

Si este orden se ve roto es solo por la entrada de lo monstruoso. En el caso de Jesús se convierte en un nuevo eje vital, trata ya no de comprender su transformación, sino que la vive, la experimenta hasta sus últimas consecuencias. Toca un límite que los demás no atreven, no atrevemos:

Todos estamos obsesionados por los límites entre la vida y la muerte. Solo el vampiro los explora, los transgrede y los modifica sin importar los medios. Un consuelo y un orgullo nos queda en nuestra amenazada condición humana: la sensación de poder que la inmortalidad le otorga también tiene su precio. Hay algo peor que la muerte, declara el vampiro en el Nosferatu de Werner Herzog. Peor es la vida, soportarla con sus frivolidades y sus cambios, que son, finalmente, superficiales, porque el hombre continúa siendo la criatura miserable y gloriosa que, acaso por sus contradicciones, se convierte en sujeto y objeto del vampiro. (Quitarte 2005: 185) 
De tal suerte, el vampiro, cada vez más alejado de su origen que lo confronta a un poder divino, se transforma en un ser que confronta el patetismo y la linealidad de la vida humana. El monstruo, cuando sale al mundo, lo posee, lo transforma de modo irremediable. Los demás, al ser "tocados" por el monstruo, ven también alterado su contexto, pero quedan imposibilitados a acceder a las formas de vida del monstruo, quien, fiel a su condición, mantiene algo oculto a quien le contempla. En Cronos, pretender vencer al monstruo supone un fracaso adelantado, pues la humanidad frágil física y espiritualmente en nada puede contra lo que se le muestra extraño y nuevo. De la Guardia y Ángel no solo verán sus objetivos perdidos en la derrota, sino que les costará la vida.

$\mathrm{Si}$, por el contrario, existe un mundo que pueda penetrar en lo monstruoso comprendiéndolo, aceptándolo, ese es el mundo infantil. En la ya citada entrevista, afirma Del Toro:

Nunca la noche es tan oscura como cuando eres un niño, nunca experimentarás la oscuridad ni el silencio de la misma forma. Quizás porque, cuando eres un niño, vives en un mundo creado por personajes más grandes que tú, y extraños a ti mismo y a tus emociones. Es como ser Gulliver: el mundo no está hecho para tu talla, emocional o físicamente. Intento mostrar con más integridad el mundo de los niños que el de los adultos, pero no hablo solo de una integridad moral, sino también psíquica y espiritual. (Serrano 2007)

Y efectivamente lo logra, los niños siempre acceden, en su filmografía, de una manera natural al contacto con lo extraño, con lo monstruoso. Hace falta simplemente observar con detalle las reacciones de Ofelia (Ivana Baquero) en El laberinto del Fauno, pues actúa con total naturalidad y firmeza tanto en su primer encuentro con un hada, así como con la aparición del fauno, pero con sorpresa (y en ocasiones horror) ante las acciones de los adultos. Lo mismo ocurre con Carlos (Fernando Tielve) en El espinazo del diablo, quien, si bien siente miedo ante la primera aparición de Santi (Junio Valverde), de a poco transforma su actitud y establece una especie de complicidad con el fantasma. Y ni qué decir de Chuy (Alexander Goodwin), el niño que, en Mimic, se puede comunicar con los insectos gigantes a través del juego de ritmos que hace con un par de cucharas. En el caso de Cronos, Aurora representa no solo el único vínculo real de Jesús con el mundo ordinario, sino que funge como una especie de extraña guía silenciosa ante el mundo de lo monstruoso ${ }^{2}$.

Solo ella parece capaz de comprender el dolor de su abuelo, sus nuevas necesidades. En un punto incluso se ofrece a sí misma como alimento. Al saber que el mundo no podrá comprender nunca aquello en que Jesús se ha convertido, Aurora se mostrará dispuesta, en su empatía, hasta a ofrecer su vida. Pero es esta misma acción la que enfrenta a Jesús con la imposibilidad de perpetuar su condición. He aquí el factor intimidad familiar que he destacado en el

\footnotetext{
${ }^{2}$ Cabe señalar, a manera de paréntesis, que la caracterización del niño como vínculo o, de hecho, como receptáculo de lo monstruoso no es, en el caso específico del cine mexicano, exclusivo de Guillermo del Toro. Gran influencia para el director jalisciense es la obra de Carlos Enrique Taboada quien, en cintas como El libro de piedra y Veneno para las hadas, otorga ambos papeles a sus personajes infantiles.
} 
preámbulo. Sin importar los alcances de la metamorfosis padecida, hay algo de la humanidad del monstruo que se mantiene (el eterno tema del doble), algo que muestra que junto con los rasgos terribles de la condición humana también existen otras caras que le permiten adentrarse en la Otredad, comprenderla. Sin embargo, este movimiento solo lo permite la monstruosidad liberada. Al final el monstruo no es cazado, no hay quien reclame el acto heroico de haberle vencido. $Y$ es que en el cine de Guillermo del Toro, los universos fantásticos siempre sobreviven, es la realidad humana la que arrebata con violencia la vida. Jesús se entrega suavemente a las consecuencias de su condición, las acepta, pues su vida ya se ha ubicado por encima incluso de su realidad. Sabe, además, que no se encuentra solo. Reproduzco la escena final tal como la describe Del Toro en su guion:

121) INTERIOR - RECÁMARA - DÍA

Los rayos del sol entran por la ventana e iluminan la habitación para revelarnos a... Jesús tendido en la cama... aceptando la luz... esperando la muerte. A su lado, Aurora. Mercedes se une a la niña, se sienta en un costado de la cama, la vida escapa del cuerpo de Jesús. Inician créditos finales; Haydn suena en la pista. Mercedes se gira lentamente hacia Aurora, como descubriéndola apenas... se abrazan fuertemente. Un cuadro apacible, clásico.

FIN. (Del Toro 1995: 108-109)

No la salvación, pero sí la aniquilación acompañada, sí la monstruosidad, pero no la soledad que destruye más cruelmente. En esta escena final queda claro que lo familiar funciona como un lazo íntimo con la vida más allá de las meras convenciones sociales; únicamente en sus terrenos es posible soportar la carga de ser diferente.

\section{ESte CUERPo QUe ES PURA HAMBRE}

En Juan de los muertos, la presencia de lo familiar como forma de intimidad a ser rescatada se muestra también, pero en un registro muy distinto al que ofreció Guillermo del Toro en su cinta ya comentada. El filme del director nacido en Buenos Aires ubica desde la primera toma su situación: Juan (Alexis Díaz de Villegas) yace postrado en una balsa. Queda clara la primera referencia a las embarcaciones improvisadas que cada día transportan a cientos de cubanos que tratan de escapar de su nación con rumbo a Miami o cualquier otro puerto cercano. De repente, Juan se asusta cuando a la balsa sube Lázaro (Jorge Molina), su mejor amigo. Empiezan una breve conversación que es abruptamente interrumpida por la aparición de un cadáver flotando en el agua. Este cobra vida y trata de atacar a los protagonistas, quienes a golpe de arpón rematan al reviniente. Ambos deciden no comentar con nadie lo ocurrido y se encaminan a tierra firme.

En los siguientes minutos, Brugués va a establecer el mundo cotidiano de los personajes ${ }^{3}$; los vemos en sus interacciones con vecinos, amigos y gente de

\footnotetext{
${ }^{3}$ Estrategia habitual en el cine de zombis. Piénsese, por ejemplo, en Shaun of the Dead del director
} 
paso. De entrada, quedan claras las dificultades que tienen Lázaro y Juan para establecer vínculos duraderos fuera de su amistad: Lázaro agrede a un tipo que le debe dinero y reconoce no ser muy cercano a su hijo. Por su lado, Juan discute con un niño, ayuda a una anciana vecina a entrar a su edificio (con lo cual se establecen las cualidades de carácter de Juan) y, sobre todo, vemos su compleja relación con su hija Camila (Andrea Duro). Por una breve conversación sabemos que la madre de Camila ha migrado a los Estados Unidos, debido a que la situación tanto en España como en Cuba le resulta insoportable. Sabemos también que Camila no confía en Juan, a pesar de que le guarda un claro afecto. Ante el rechazo de su hija, Juan se encamina a casa de Lucía (Susana Pous), su vecina y amante con quien lleva fugaz relación.

En la escena siguiente, no solo va a cerrar este círculo de presentación del mundo cotidiano de los personajes, sino que va a desarrollar el conflicto. Vemos a un grupo de gente, dirigidos por una mujer, cantar el himno nacional cubano; la cámara avanza y nos descubre a Juan y Lázaro ya acompañados por el hijo de este último: Vladi (Andros Perugorría), el Primo (Eliécer Ramírez) y La China (Jazz Vila). El cuadro es pintoresco ya por sí mismo, pues las cualidades físicas y personales de cada integrante del quinteto destacan. No solo eso, sino que es claro que los protagonistas no están integrados en su comunidad; la toma los excluye y marca claramente. De hecho, conforme la escena transcurre, nos enteramos de que nadie en el grupo es un ejemplo de honestidad. El primer ataque zombi desata una locura colectiva, pero sirve a Juan y sus compañeros para salir de un posible embrollo. Hay un corte y se ve el ataque zombi, pero ahora cubierto por un noticiero local. El periodista en pantalla se refiere a los muertos vivientes como "disidentes". He aquí dos grandes aciertos en el planteamiento de la cinta: primero, el no dar un origen definido al virus. Si bien existen referencias al brote de "un nuevo tipo de virus", el asunto nunca es explicado. Segundo, el nombre dado a los monstruos: llamarlos disidentes permite al director enfatizar la carga política de su historia, le da un sentido plenamente reconocible para quienes están familiarizados con el léxico revolucionario en Cuba y, sumado al origen jamás aclarado de los seres monstruosos, permite establecer como causantes del conflicto a los imperios "enemigos de la libertad".

Y es que, si bien en su origen mítico tiene que ver con ritos vudú de Haití y otras zonas vecinas, desde su llegada al cine o, más precisamente, desde su llegada al cine con la célebre cinta de George A. Romero, el zombi ha servido como una reflexión de la masa irracional que devora todo a su paso, en especial la voluntad individual que trata de preservar sus nociones de libertad. Si el origen de estos seres ha variado ya en tantas formas es porque dichas variantes los hacen más cercanos a las condiciones y preocupaciones del momento específico en que se insertan. Ahora bien, ante la profunda repetición y el abuso extremo en el uso de zombis del cine de horror contemporáneo, son pocos los productos que ofrecen variantes frescas al subgénero. El hecho de que Brugués adapte la

inglés Edgar Wright. Es importante en esta clase de cintas establecer el mundo ordinario para hacer un comparativo de las acciones de los integrantes de dicho mundo una vez transformados. 
situación a la Cuba actual da un giro original no solo a la mirada sobre estos monstruos, sino a la mirada de la situación social y cultural de la isla.

De tal modo, los personajes de Juan de los muertos no hallan salida alguna para los problemas de la isla caribeña. Mucho antes de que el asunto con los "disidentes" se desate, sienten que el país ya iba en picada. Juan no ve para sí más que quedarse y resistir, ya la cosa mejorará. En cambio, Vladi deja en claro su postura:

VLADI: Yo quiero irme pal carajo de aquí y darle la vuelta al mundo. Si me preguntan de dónde soy, diré que de Cuba. Si me preguntan qué es Cuba, diré que es una islita socialista del Caribe. Si me preguntan que es socialismo, diré que es un sistema instaurado por Fidel Castro hace cincuenta años. Si me preguntan quién es Fidel Castro... Me quedo a vivir ahí para siempre. (Brugués 2012: 21' 20")

Apenas ha terminado estas palabras y su padre, Lázaro, ya lo elogia afirmando que llegará mucho más lejos que él. Lo familiar de nuevo destacado, esta vez a través de la desgracia. Valor que se confirma en la escena siguiente cuando Juan trata de ayudar a su anciana vecina con su marido aparentemente muerto o, para mejor decir, muerto y reanimado por la plaga. En toda la escena se enfatiza el valor del ser amado incluso en su condición monstruosa. La escena acaba de manera accidentada con la muerte de ambos ancianos. El conflicto se ha desatado ya del todo.

Juan tiene como primera prioridad ir por su hija Camila, sacarla del caos que acarrea la situación de los "disidentes", pero una vez realizado este objetivo, la prioridad es otra: sacar el mayor beneficio de todo el asunto. Juan reúne un pequeño ejército personal con el que va a salir a acabar con los "disidentes" y cobrar treinta pesos por cada aniquilación. Todo bajo el lema: "Juan de los muertos. Matamos a sus seres queridos. ¿En qué puedo ayudarle?".

Lo familiar, lo íntimo, salta de nuevo al paso. No solo en el cine de zombis, sino en mucho del cine de horror, son típicas las escenas en que un personaje no puede acabar con la vida de un ser querido, por más que este haya sido transformado en un monstruo. Las implicaciones de cercanía y de afecto se interponen en los héroes de turno. La masa informe, la multitud devoradora es otra cosa: no tiene un rostro reconocible, personificable al menos. Juan de los muertos juega hábilmente con ambas posibilidades. Por un lado, el grupo de Juan no tiene piedad alguna contra los "disidentes" que halla a su paso en las calles. Por otro, en su éxtasis de sangre, son incapaces de reconocer a quien está vivo (como ocurre en el caso del motorista caído al que Lázaro golpea la cabeza contra el piso), o bien el que estén vivos deja de tener importancia, como ocurre en la escena en la que Lázaro mata sin piedad al hombre que le debe dinero, o bien en la hilarante escena en que Lázaro y Vladi abandonan al hombre en silla de ruedas para poder llevar sobre esta las cajas de ron:

JUAN: ¿y el viejo?

LÁZARO: Falleció. Tuvimos que dejarlo.

VLADI: No necesariamente en ese orden. (Brugués 2012: 47' 20") 
En estos casos la ironía es el recurso fundamental de la narración en pantalla. Brugués prescinde de la escena sentimental en la que los personajes enfrentan el rostro de algún ser cercano convertido en "disidente", al contrario, los evita, sin dejar de mostrarlos para dejar ver, más bien, las cualidades de sus personajes, que son complejos y no unidimensionales. Así, la ironía pasa del mero recurso humorístico a un recurso de valor y desarrollo de personajes. Tal vez el momento en que más se acentúa dicha situación es en las escenas en que Juan y su séquito enfrentan a los paramilitares ávidos de poder y de instaurar un nuevo orden que les beneficie, y aquellas en que son rescatados por el ministro estadounidense. En el primero de los casos, el nuevo grupo que aspira al poder luce torpe, ciertamente están bien armados, pero no listos para lo que enfrentan. Su discurso, según lo pueden observar los personajes centrales, es el mismo de los últimos cincuenta años solo que con un rostro distinto. Por su parte, el ministro se ve a sí mismo como un salvador (así como la "democracia" a la que representa), ni siquiera entiende el idioma de aquellos a los que ha ayudado, mucho menos sus necesidades. Se encuentra perdido en su victorioso discurso, en su plan de rescate para todos. Un arponazo suelto "por accidente" por Lázaro acaba con todo el asunto.

Cabe apuntar que en ningún momento Brugués toma una postura en cuanto a las ideologías que satiriza en su película. Todas quedan burladas, lo cual hace más potente su crítica. Al final, si hay algo importante para los personajes es la amistad, la solidaridad y la familia: Juan se ofrece ciegamente a los falsos deseos sexuales de Lázaro (cede a una broma que, malicioso e irónico, le gasta su amigo), salva al niño con que discutiera en los primeros minutos y, lo más importante, pone en marcha el plan para salvar a quienes le importan. En sus últimas líneas ha de expresar que él no puede seguirlos en el camino, es el que se queda, el que se ofrece para que los otros puedan seguir, mas ya no en tono mesiánico, sino en la dinámica de aquel que prefiere quedarse en ese mundo que, aunque hostil, le es familiar:

\section{LÁZARO: Sube Juan.}

Juan niega con la cabeza al tiempo que empuja la embarcación.

CAMILA: Juan, tú no puedes hacer eso.

JUAN: Debí hacerlo desde el principio. A lo mejor las cosas no se ponían tan mal.

LÁZARO: Juan, no seas maricón y sube al carro, dale.

JUAN: Yo soy un sobreviviente. Sobreviví a Mariel, sobreviví a Angola, al Periodo especial y a la cosa esta que vino después y voy a sobrevivir a esto. Igual la gente me ve y se va uniendo para ayudar. Aquí yo estoy bien. Esto me gusta. ( $A$ Camila) allá tú tienes a tu mamá, ella te va a cuidar. Le das un beso de mi parte. (Brugués 2012: 89' 23")

Si se arroja a la multitud informe de "disidentes" es porque termina con la actitud del cazador de monstruos, aquel que sabe que la derrota no es la muerte sino la renuncia al combate con el monstruoso enemigo. Ahab enfrenta a la ballena blanca con la certeza de su derrota, que no es sino su victoria final. El que 
caza monstruos ya no puede vivir sin ellos, pues la vida se le ha transformado con base en extrañezas.

\section{Colofón}

A través de este rápido vistazo a las cintas La invención de Cronos y Juan de los muertos, he tratado de establecer la noción de tropigótico cinematográfico no como quien tiene el afán de establecer una categoría analítica definitiva, sino más bien como el cinéfilo (cinéfago acaso) que encuentra elementos de una voz. Voz distinguible en ciertas geografías con todo lo que su carga cultural representa y que desde ahí se comparte a otras latitudes. Y es que, de nuevo, al hablar de las características del cine de horror latinoamericano (así como el de cualquier otro lugar y género), se debe tomar en cuenta no una tradición que se ha formado en sentido lineal, sino una tradición que se nutre de otras formas de reconocer la imagen y la sensibilidad, y no solo del cine, sino de la literatura y otras formas de expresión.

La fábrica de De la Guardia, que se eleva en el paisaje urbano de Ciudad de México, es el castillo monstruoso que sirviera al vampiro victoriano para atraer a sus víctimas. Ángel es el sirviente, no tan leal, pero sí entregado. Ambos humanos, pero, tal vez por ello, más monstruosos que el vampiro que viene a hacerles frente. Fábrica que es resguardo de lo más putrefacto de un ser humano perdido en la asepsia de un mundo perdido en sus propias ambiciones y deseos. En Guillermo del Toro, el monstruo no es un ser de naturaleza maligna, es un ser complejo que enfrenta al ser humano con facetas que de sí mismo ha dejado olvidadas.

En Juan de los muertos, el monstruo es la multitud hambrienta, la que devora sin consideración alguna, con toda su carga ideológica y situacional. La única posibilidad de sobrevivir al monstruo es confrontarlo directamente.

En ambas cintas el reflejo de lo familiar es explorado ampliamente, pero no desde una perspectiva moralina o sensibilera, sino en un sentido que conecta con lo íntimo y que, al serlo, es capaz de abrir la mirada a lo Otro, a lo diferente, sin importar el rostro que cobre. Lo mismo para otras tantas cualidades de la cultura latinoamericana: no hay una caracterización, sino aproximaciones, reflexiones (en el sentido más especular de la palabra) y posibilidades. Posibilidades de hallar una identidad latinoamericana que no corra en un solo sentido sino en muchos, identidad que puede ser explorada desde el humor, pero también desde el miedo, desde ese rostro revelador y oculto que es el monstruo. Si como afirma Deleuze, lo importante al tratar de acceder a la obra artística no es establecer significados, sino conexiones con nuestro mundo, con nuestra realidad, tal vez sea este el mejor momento para dar la cara a esos géneros a veces hechos de lado, pero que, sin grandes pretensiones, permiten, joh monstruosa revelación!, transfigurar el mundo en un rostro apenas reconocible, pero pleno de puntos de encuentro. 
OBRAS CITADAS

Brugués, Alejandro (2011): Juan de los muertos, España-Cuba, La Zanfoña Producciones.

Chaves, José Ricardo (1995): Cuentos tropigóticos. México, UNAM.

De León Ramírez, Francisco Javier (2011): Prometeo en llamas: metamorfosis del monstruo. México, UNAM-Vejamen.

Del Toro, Guillermo (1993): La invención de Cronos. México, IMCINE.

- (1995): La invención de Cronos. México, Ediciones El Milagro.

Frenzel, Elisabeth (1980): Diccionario de motivos de la literatura universal. Madrid, Gredos.

Freud, Sigmund (1997): Obras completas XVII, traducción de José Luis Etcheverry. Madrid, Amorrortu.

Quirarte, Vicente (2005): Del monstruo considerado como una de las bellas artes, México, Paidós.

Serrano, Alejandro (2007): "Guillermo del Toro habla sobre la fantasía, el terror y Hellboy 2". http://www.fantasymundo.com/noticias/3824/guillermo_toro_habla_ fantasia terror_hellboy_2. Última visita: 27.08.2012.

Taboada, Carlos Enrique (1968): El libro de piedra. México, Producciones AGSA.

- (1984): Veneno para las hadas. México, IMCINE/STPC. 